\title{
Age Prediction in the Adult Based on the Pulp-to-Tooth Ratio in Lower Third Molars: A Cone-beam CT Study
}

\author{
Predicción de Edad en el Adulto Basada en la Proporción Pulpa-a-Diente \\ en Terceros Molares Inferiores: Un Estudio por TC de Haz de Cono
} Firas Alsoleihat ${ }^{1}$; Mohammad H. Al-Shayyab ${ }^{2}$; Heba Kalbouneh ${ }^{3}$; Heba Al-Zer ${ }^{1}$; Soukaina Ryalat ${ }^{2}$;
Abeer Alhadidi ${ }^{2}$; Hamza Saoud ${ }^{4}$; Ashraf I. Shaweesh ${ }^{5}$; Salah A. Al-Omoush ${ }^{6}$ \& Ameen Khraisat ${ }^{1}$

ALSOLEIHAT, F.; AL-SHAYYAB, M. H.; KALBOUNEH, H.; AL-ZER, H.; RYALAT, S.; ALHADIDI, A.; SAOUD, H.; SHAWEESH, A. I.; AL-OMOUSH, S. A. \& KHRAISAT, A. Age prediction in the adult based on the pulp-to-tooth ratio in lower third molars: a conebeam CT study. Int. J. Morphol., 35(2):488-493, 2017.

SUMMARY: Estimation of age-at-death is an integral part of the identification process of individuals in many forensic odontology cases where their identity cannot be determined by visualization or other ways. Dental age estimation in the adult is more challenging as most of the dentition is completely developed by 18 years of age. This study employs a mesio-distal (MD) pulp-to-tooth ratio taken at the neck of lower third molars (LM3) to provide an estimation of age at the time of radiographic imaging based on the well-known fact that pulp volume tends to decrease with advancing age due to continued apposition of secondary dentine throughout adulthood. A total of 155 Conebeam computed tomography (CBCT) radiographs of LM3s for a random sample of 155 Jordanian Arabs $(80$ females, 75 males; age range $=$ $18-58$ years, mean age $=28.2$ years, $\mathrm{SD}=10.0$ years) were used. Both pulp and tooth MD diameters were measured at the neck. MD pulp-totooth ratios for LM3s were linearly regressed against age. Statistically significant negative association was found between an individual's age at the time of imaging and the MD pulp-to-tooth ratio taken at the neck. Specifically, the strength of the association is $\mathrm{r}=-0.361$, which means only $13.0 \%$ of the variation in age can be explained by the MD pulp-to-tooth ratio taken at the neck. Therefore, it was concluded that MD pulp-to-tooth ratio taken at the neck of LM3s is not a reliable predictor of chronological age in adults, possibly due to the large variation in the timing of LM3 development.

KEY WORDS: Estimation of age-at-death; Forensic odontology; Archaeology; Paleontology; Dental age estimation; Third molars.

\section{INTRODUCTION}

Accurate estimation of age-at-death of unknown individuals from their body and/or dental remains is of crucial importance in many forensic cases, where this information is needed to help law enforcement officials in identifying the individual to whom the remains belong (Panchbhai, 2011; Gupta et al., 2014; Verma et al., 2014). Examples of such cases include identification of the dead involved in criminal cases as well as the extremely mutilated victims of mass disasters such as natural catastrophes, accidents and homicidal attacks (terrorist bombing) (Gupta et al.; Verma et al.). In addition, dental age estimation is of crucial importance for age-at-death assessment of human skeletons recovered from archaeological contexts (Maber et al., 2006). Moreover, dental age estimation is undertaken on the living, particularly when birth data are missing or suspicious, for various reasons such as school attendance, marriage, premature births, adoption, orthodontics, pediatric endocrinology, immigration, eligibility for some social benefits, penal trials, and legal actions in cases such as rape and kidnapping (Whittakar \& McDonald, 1989; Ciapparelli, 1992; Cameriere et al., 2004; Maber et al.; Cameriere et al., 2007; Masthan, 2009a,b).

\footnotetext{
${ }^{1}$ Department of Conservative Dentistry and Fixed Prosthodontics, School of Dentistry, University of Jordan, Amman 11942, Jordan.

${ }^{2}$ Department of Oral and Maxillofacial Surgery, Oral Medicine, Oral pathology and Periodontology, School of Dentistry, University of Jordan, Amman 11942, Jordan.

${ }^{3}$ Department of Anatomy and Histology, School of Medicine, University of Jordan, Amman 11942, Jordan.

${ }^{4}$ Recent Graduate Interns, School of Dentistry, University of Jordan, Amman 11942, Jordan.

${ }^{5}$ Department of Oral Medicine and Oral Surgery, Faculty of Dentistry, Jordan University of Science and Technology, Irbid 22110, Jordan.

${ }^{6}$ Department of Removable Prosthodontics, School of Dentistry, University of Jordan, Amman 11942, Jordan.
} 
Teeth are the most durable structures in vertebrates due to their high level of mineralization, and thus, in contrast to the other parts of the body including the skeleton, are very resistant to organic decay as well as to peri- and postmortem destruction by external factors such as fire and severe traumas (Tobias, 1991; Ciapparelli; Holden et al., 1995; Babar et al., 2008; Carvalho et al., 2009; Masthan, 2009a). In addition, dental remains sometimes are the only source of information for age estimation especially when the other parts of the body are extremely damaged to a degree where they are no longer adequate to provide the foundation for accurate analyses, such as skeletal elements-based age assessment methods (Gupta et al.; Verma et al.). Moreover, age estimation based on tooth formation is generally considered more accurate than those based onskeletal development and maturation-at least for children and adolescents - as odontogenesis is under greater genetic control and hence is less influenced by environmental and nutritional factors as well as endogenous disturbances such as disease and hormonal changes (Ciapparelli; Willems, 2001; Ardakani et al., 2007; Babar et al.; Carvalho et al.; Masthan, 2009a).

There are a number of accurate methods commonly used for dental age estimation in human fetuses and newborns, such as the method of Kraus \& Jordan (1965) and others (Whittakar \& McDonald; Masthan, 2009a,b). These methods rely on the degree of calcification and development of the primary dentition and the first permanent molar, over the period from 4 months in utero until the end of the first year of age.

There are also many more approaches for dental age estimation in children and adolescents with approximate accuracy of 1.6 years (Verma et al.). Examples of these methods include those of: Schour \& Massler (1941), Moorrees et al. (1963), Demirjian et al. (1973, 1999), and Nolla (1960). These methods are generally based on the degree of tooth calcification and the timing of a number of morphologically distinct developmental stages, such as first evidence of calcification, crown completion, eruption/ emergence, and root completion. There are also methods based upon measurements of open apices and they can be used with relative accuracy in children and adolescents between five and 15 years of age (Cameriere et al., 2006; Rai \& Anand, 2007).

However, dental age estimation in adults is generally considered more challenging. This is because most of the dentition has completed development by young adulthood (Panchbhai; Verma et al.). Nevertheless, there are number of approaches used for this purpose, such as Gustafson's method (Gustafson, 1950); the modified Gustafson's method or Johnson's method (Willems); Kvaal et al. (1995) pulpto-tooth ratio method; the coronal pulp cavity index method (Drusini, 2008); a method based on occlusal tooth wear (Yun et al., 2007); a method based on incremental lines of cementum with claimed accuracy of 2-3 years (Aggarwal et al., 2008); third molar development-based methods, such as that of Harris \& Nortjé (1984) and by Van Heerden (1985); in addition to other techniques based on dentin translucency (Lorentsen \& Solheim, 1989) and aspartic acid racemization (Ritz-Timme et al., 2000; Avon, 2004). In general, the methods based on attrition and third molar development are considered unreliable for adult age estimation, while the ones based on occlusal tooth wear, pulp-to-tooth ratios, incremental lines of cementum are considered reliable, and the most accurate of these so far are those based on dentin translucency and aspartic acid racemization (Gupta et al.; Verma et al.).

In general, the age estimation methods that are based on pulp-to-tooth ratios including the coronal pulp cavity index, whether two-dimensional (Kvaal et al.; Drusini) or volumetric (Vandevoort et al., 2004; Yang et al., 2006) are considered reliable and can be taken as a guide for age prediction in the adult (Kvaal et al.; Vandevoort et al.; Yang et al.; Drusini; Achary \& Sivapathasundharan, 2009; Masthan, 2009a). In contrast, the reliability of age estimation in adults using the methods based on third molar development is questionable due to the great variation in its development (Panchbhai; Gupta et al.; Verma et al.). Olze et al. (2005) compared the validity of the use of a number of methods adopting third molar development as an age predictor for the adult, especially when the question is whether the individual is under the age of 18 years or not. The methods compared were those of Gleiser \& Hunt (1955), Demirjian et al. (1973, 1999), Gustafson \& Koch (1974), Harris \& Nortjé and Kullman et al. (1992). They found that the Demirjian method was the most accurate one for this purpose. So far, as mentioned earlier, the most precise methods reported for age prediction in the adult in forensic contexts are the ones based on dentin translucency (Lorentsen \& Solheim) and on aspartic acid racemization (Ritz-Timme et al.; Avon).

It is well known in dentistry that there are two types of physiologic dentin; primary dentin, which is deposited before root formation is complete, and secondary dentin, which is formed after root completion and continues to be formed throughout life (Panchbhai). The direction of growth for both of these types is toward the center of the tooth and hence, at the expense of dental pulp size. Bodecker (1925) found that the amount of secondary dentin apposition to be positively correlated with the chronological age of the individual. In 2008 Drusini argued that age has greater influence 
ALSOLEIHAT, F.; AL-SHAYYAB, M. H.; KALBOUNEH, H.; AL-ZER, H.; RYALAT, S.; ALHADIDI, A.; SAOUD, H.; SHAWEESH, A. I.; AL-OMOUSH, S. A. \& KHRAISAT, A. Age prediction in the adult based on the pulp-to-tooth ratio in lower third molars: a cone-beam CT study. Int. J. Morphol., 35(2):488-493, 2017.

on secondary deposition than attrition or irritation as more secondary dentin is normally deposited on the floor of the coronal pulp cavity than on the roof. Thus, it is expected that the age of the individual can be reliably estimated from the total dentin thickness relative to the dental pulp diameter at the same cross sectional tooth level.

The aim of the present study is to investigate the reliability of estimating the chronological age of adult individuals based on the pulp-to-tooth diameter ratio at the neck of lower third molars (LM3). Neck level was chosen because at this level the thickness of both the enamel covering the crown dentin and the cementum covering the root dentin come down to feather edge thickness (i.e. approaching zero). Thus, measuring tooth diameter at the neck is technically the total dentin thickness minus pulp diameter. Third molar teeth were chosen for this study because of their relative availability as sound teeth.

\section{MATERIAL AND METHOD}

The sample upon which this study is based consists of a random sample obtained in 2016 by selecting 155 cone beam computed tomography (CBCT) radiographs of lower third molars that belong to 155 living Jordanian individuals (80 females and 75 males) who attended the Dental section of the Jordan University Hospital. All of these CBCT radiographs were taken for other therapeutic reasons. It is noteworthy to mention that the Dental section of the Jordan University Hospital is one of the main referral centers for third molar teeth extraction in the capital city of Amman, where about half the population of Jordan reside, and which has a large proportion of its residents originally belonging to other geographic areas of Jordan, according to the 2015 Population and Housing Census conducted by the Department of Statistics in Jordan. In addition, it is noteworthy to mention that the dental care at this center, although relatively expensive, is accessible to all referred patients regardless of their socio-economic status and this is mainly due to the fact that almost all the expenses are covered by various types of medical insurance, and even those who do not have such insurance, have access to have the expenses of their treatment covered by a special royal fund. Thus, even the poor who live in Amman are aware of, and have access to, this relatively expensive dental care. As such, the authors believe the sample utilized in this study is likely representative of the living Jordanian population as a whole. In this regard, it is noteworthy to mention that it is important in such studies which investigate the correlation between decrease in pulp size and age, to make sure that the employed sample ought to include individuals that belong to a wide range of socio-economic background in order to insure the representativeness of the sample employed to the geographic population being investigated. That is due to the likelihood that economically advantaged sample exhibit patterns of development-including odontogenesis and secondary dentin apposition-that differ from those suffering from long-standing undernutrition.

The selected individuals ranged in age from 18 to 58 years $(S D=10.0)$, with an average age of 28.2 years. Individuals included in the sampling frame included those that met the following criteria: 1) healthy with no history of serious illnesses that may adversely affect tooth development, 2) no developmental anomalies, such as ectodermal dysplasia, facial clefts or craniofacial syndromes, and 3) and possessing impacted or erupted third molars but not in occlusion, of normal appearance, and unaffected by caries and/or attrition. It is noteworthy to mention that third molars in occlusion were excluded from the sample because it is not clear whether the rate of dentin growth in impacted or erupted teeth but not in occlusion, which is often the case among third molars, is same as that of teeth in normal occlusion, given that no previous studies have addressed this question. Medical and dental records were checked for each participant to bolster the accuracy of the selection criteria. Informed written consent was obtained from all individuals who chose to participate in the study. Appropriate ethical approval for this type of study was obtained from the authorized body, the Ethical Committee of Jordan University hospital/University of Jordan, prior to the commencement of the study.

Each tooth image was cross-sectioned at the level of the neck. For each cervical cross-sectional image, the mesiodistal (MD) diameter of the pulp and the MD diameter of the tooth were measured using the computer-compatible Cone beam CT program. The ratio between these two diameters was calculated for each tooth. The measured MD tooth diameter was the greatest distance between the mesial and distal surfaces of the tooth image cross-sectioned at the neck. Likewise the MD diameter of the pulp was the greatest distance between the mesial and distal peripheries of the pulp taken at the same cervical cross-section. All measurements were rounded to the nearest 0.01 millimeter.

One well-trained examiner recorded all of the measurements employed in the present investigation to eliminate errors due to inter-observerdifferences. Furthermore, all cross sectional images used in the present study were re-measured by the same assessor. SPSS Intraclass Correlation Coefficient (ICC) statistic was used to evaluate the reliability of the measurements conducted on these images. 
SPSS, Ver. 17.0 was used to analyze the data. Pearson's correlation test was used to assess the strength of the correlations between age to the ratio between MD pulp and tooth diameters at the cervical cross-sections. In accordance with Cicchetti (1994) absolute values of Pearson's correlation coefficient ranging between 0-0.39 were regarded as weak, $0.40-0.59$ as moderate, $0.60-0.74$ as strong, and $0.75-1$ as very strong correlation. Correlations were considered statistically significant if $\mathrm{p}$-values were less than 0.05 .

The CBTC images of the lower third molar teeth of the participants in the present study are currently available at the School of Dentistry of the University of Jordan.

\section{RESULTS}

The ICC, which is used in the present study to assess intra-observer differences and is read as the degree of association between measurement sessions, was $0.85 \mathrm{p}=$ $0.000)$ and $0.87(\mathrm{p}=0.000)$, respectively, for the two mensurational variables used in the present study (i.e. LM3 MD tooth diameter, LM3 MD pulp diameter). This indicated, for both variables, excellent correlation between the two measurement sessions, and that the intra-observer error was random and statistically insignificant.

A statistically significant, but weak negative correlation was found between the LM3 pulp-to-tooth ratio at the neck and the individual's age at the time of imaging $(r=-0.361, p=0.015)$. Hence, linear regression established that LM3 pulp-to-tooth ratio at the neck can predict the individual's age at the time of imaging with statistical significance, however, the individual's age at the time of imaging accounted only for $13.0 \%$ of the explained variability in LM3 pulp-to-tooth ratio at the neck.

\section{DISCUSSION}

It is generally agreed within the field of forensic odontology that optimum estimates of age can only be achieved through a multifactorial approach; that is, employing as many valid methods and techniques of dental age assessment as applicable to the specific case (Panchbhai; Gupta et al.; Verma et al.).

In addition, it is also well known that dental development shows variation between individuals of the same population and between individuals of different regio- nal population groups (Ciapparelli; Olze et al.; Kuritai et al., 2007; Achary \& Sivapathasundharan). Thus, it is recommended that any dental age estimation method, even the most reliable ones, should be calibrated to the local population concerned prior to its application, so that potential over- or underestimation of age can be minimized (Ciapparelli; Olze et al.; Kuritai et al.; Achary \& Sivapathasundharan). In this regard, it should be underlined that age estimation in forensic cases, in contrast to clinical situation, is required to be of optimal accuracy, as potential over- or underestimation of age might lead to a failure of justice (Ciapparelli; Ardakani et al.; Karjodkar, 2009; Panchbhai). As such, the following requirements are mandated for the purpose of age estimation in forensic context: obtaining appropriate radiographs and specimens from the subject, the obtained material should be similar to the one used in the selected age prediction method so that direct and valid comparisons can be conducted, selection of the appropriate age prediction method is based on one's understanding of the method and its suitability to the subject, besides understanding and compliance with the legal requirements (Ciapparelli; Panchbhai).

As the method of the present study relies on measurements conducted on cone beam $\mathrm{CT}$ radiographs, it is considered more advantageous than the ones that rely on microscopic measurements obtained by histological section and thus criticized for being invasive and inappropriate for age prediction in the living and in some cases of the dead.

Because of the limited sample size ( 80 females, 75 males) of the present study, males and females could not be dealt with separately. It is noteworthy to mention in this regard that in some forensic cases the sex of the deceased individual cannot be identified due to severe peri- or postmortem damage to the skeleton and soft parts of the body; however, teeth often survive such damage. In such cases, we believe age estimation would be more accurate when conducted by using methods or surveys that do not deal with males and females separately. In this regard, it is worth noting that Van Heerden compared third molar development between males and females and found no significant differences between them. The majority of dental age assessment methods and surveys do not treat the two sexes differently, and are thus applicable to both sexes. Exceptions of these include those of Demirjian et al. (1999), Solari \& Abramovitch (2002) and Nolla which treat the two sexes differently.

According to the coefficient of correlation $(r=-0.361)$, and then the correlation between age and the pulp/tooth value is not strong. In addition, the coefficients of determination ( $\mathrm{R}$ squared $=13.0 \%$ ) for the regression equation is very low 
ALSOLEIHAT, F.; AL-SHAYYAB, M. H.; KALBOUNEH, H.; AL-ZER, H.; RYALAT, S.; ALHADIDI, A.; SAOUD, H.; SHAWEESH, A. I.; AL-OMOUSH, S. A. \& KHRAISAT, A. Age prediction in the adult based on the pulp-to-tooth ratio in lower third molars: a cone-beam CT study. Int. J. Morphol., 35(2):488-493, 2017.

and means that only $13 \%$ of the variation inage can be explained by the MD pulp-to-tooth ratio taken at the neck of the tooth. Therefore, in this situation, a serious and unavoidable bias affects the estimates of the model It is also known that age-estimation equations derived from inverse regression analysis (as is the method employed in this study) is highly influenced by the age composition of the samples on which regression was performed (reference sample), when correlation is not strong enough $(|\mathrm{r}|<0.9$, according to BocquetAppel \& Masset, 1982). This is known as the "age mimicry problem". Generally, age estimation derived from such an equation tends to underestimate ages when reference sample is dominated by young individuals, and overestimate them when reference sample is dominated by old individuals. The degree of this bias depends on how much age distribution of the population from which the target of age estimation originates (target population) differs from that of reference sample. The age distribution of reference sample is so young in this study (mean: 28.2 , range: $18-58$ years old) that target population should often distribute older than this age distribution in actual cases (perhaps especially in forensic cases), and then those equations will predictably tend to underestimate the target ages. In addition, Aykroyd et al. (1997) noted that linear regression models tend to overestimate age in juveniles and underestimate it in adults. Therefore, it is important in such situations to make clear the possible biases and restrict the range of application to certain cases where, for example, the possible age range can be expected to be below 40 by other age estimation methods. However, if this option would make the method valueless, another option might be a Bayesian approach. Besides, if the large variation of third molar in its shape and/or timing of the development are to be the primary disturbance, using another type of tooth with smaller variation may have to be considered as an alternative.

\section{CONCLUSIONS}

As the correlation value of $r=-0.361$, found in the present study, for the mandibular third molars is so low, then only a slightly just above one-tenth (13\%) of the variation in age can be explained by the MD pulp-to-tooth ratio taken at the neck of the tooth. This value is far too low to be employed in forensic cases, and no such method could be found to be in accordance with the Daubert standard. Thus, it was concluded that MD pulp-to-tooth ratio taken at the neck of mandibular third molars is not a reliable predictor of chronological age in the adult. This is possibly due to the large variation of third molar in its shape and/or timing of the development. If these are to be the primary disturbance, using another type of tooth with smaller variation may have to be considered as an alternative.

\section{ACKNOWLEDGEMENTS}

This work was supported by the School of Dentistry of the University of Jordan. This research did not receive any specific grant from funding agencies in the public, commercial, or not-for-profit sectors.

ALSOLEIHAT, F.; AL-SHAYYAB, M. H.; KALBOUNEH, H.; AL-ZER, H.; RYALAT, S.; ALHADIDI, A.; SAOUD, H.; SHAWEESH, A. I.; AL-OMOUSH, S. A. \& KHRAISAT, A. Predicción de edad en el adulto basada en la proporción pulpa-adiente en terceros molares inferiores: Un estudio por TC de haz de cono. Int. J. Morphol., 35(2):488-493, 2017.

RESUMEN: La estimación de la edad es una parte integral del proceso de identificación de los individuos, en muchos casos en odontología forense donde la identidad no puede ser determinada por visualización u otras formas. La estimación de la edad dental en el adulto es aún más difícil ya que la mayor parte de la dentición se desarrolla completamente a los 18 años de edad. Este estudio emplea una relación mesio-distal (MD) de pulpa a diente tomada a nivel del cuello de los terceros molares inferiores (LM3) para proporcionar una estimación de la edad en el momento de la imagen radiográfica basada en que el volumen de pulpa tiende a disminuir con el avance de la edad debido a la continua posición de la dentina secundaria a lo largo de la edad adulta. Se examinaron un total de 155 radiografías de LM3 en una muestra aleatoria de 155 árabes jordanos (80 mujeres, 75 varones), rango de edad $=18-58$ años, edad media $=28,2$ años, $D E=10,0$ años. Específicamente, la fuerza de la asociación es r=0,361, lo que significa que sólo el 13,0 \% de la variación en la edad puede explicarse por la proporción pulpa-a-diente.

PALABRAS CLAVE: Estimación de la edad a la muerte; Odontología forense; Arqueología; Paleontología; Estimación de la edad dental; Terceros molares.

\section{REFERENCES}

Achary, A. B. \& Sivapathasundharan, B. Forensic Odontology. In: Rajendran, R. \& Sivapathasundharan, B. (Eds.). Shafer's Textbook of Oral Pathology. $6^{\text {th }}$ ed. New Delhi, Elsevier, 2009.

Aggarwal, P.; Saxena, S. \& Bansal, P. Incremental lines in root cementum of human teeth: an approach to their role in age estimation using polarizing microscopy. Indian J. Dent. Res., 19(4):326-30, 2008.

Ardakani, F.; Bashardoust, N. \& Sheikhha, M. The accuracy of dental panoramic radiography as an indicator of chronological age in Iranian individuals. J. Forensic Odontostomatol., 25(2):30-5, 2007.

Avon, S. L. Forensic odontology: the roles and responsibilities of the dentist. J. Can. Dent. Assoc., 70(7):453-8, 2004.

Aykroyd, R. G.; Lucy, D.; Pollard, A. M. \& Solheim, T. Technical note: regression analysis in adult age estimation. Am. J. Phys. Anthropol., 104(2):259-65, 1997.

Babar, M. G.; Iqbal, S. \& Jan, A. Essential guidelines for forensic dentistry. Pak. Oral Dent. J., 27:79-84, 2008.

Bocquet-Appel, J. P. \& Masset, C. Farewell to paleodemography. J. Hum. 
Evol., 11(4):321-33, 1982.

Bodecker, C. F. A consideration of some of the changes in the teeth from young to old age. Dent. Cosm., 67:543-9, 1925.

Cameriere, R.; Ferrante, L.; Belcastro, M. G.; Bonfiglioli, B.; Rastelli, E. \& Cingolani, M. Age estimation by pulp/tooth ratio in canines by mesial and vestibular peri-apical X-rays. J. Forensic Sci., 52(5):1151-5, 2007.

Cameriere, R.; Ferrante, L. \& Cingolani, M. Precision and reliability of pulp/tooth area ratio (RA) of second molar as indicator of adult age. $J$. Forensic Sci., 49(6):1319-23, 2004.

Cameriere, R.; Ferrante, L. \& Cingolani, M. Age estimation in children by measurement of open apices in teeth. Int. J. Legal Med., 120(1):49-52, 2006.

Carvalho, S. P. M.; da Silva, R. H. A.; Lopes-Júnior, C. \& Peres, A. S. Use of images for human identification in forensic dentistry. Radiol. Bras., 42(2):125-30, 2009.

Ciapparelli, L. The Chronology of Dental Development and Age Assessment. In: Clark, D. H. (Ed.). Practical Forensic Odontology. Oxford,Wright Butterworth-Heinemann Ltd., 1992. pp.22-42.

Cicchetti, D. V. Guidelines, criteria, and rules of thumb for evaluating normed and standardized assessment instruments in psychology. Psychol. Assess., 6(4):284-90, 1994.

Demirjian, A.; Goldstein, H. \& Tanner, J. M. A new system interpretation. Washington D. C., Taraxacum, 1999.

Demirjian, A.; Goldstein, H. \& Tanner, J. M. A new system of dental age assessment. Hum. Biol., 45(2):211-27, 1973.

Drusini, A. G. The coronal pulp cavity index: A forensic tool for age determination in human adults. Cuad. Med. Forense, 14(53-54):23549, 2008

Gleiser, I. \& Hunt, E. E. Jr. The permanent mandibular first molar: its calcification, eruption and decay. Am. J. Phys. Anthropol., 13(2):25383, 1955.

Gupta, S.; Agnihotri, A.; Chandra, A. \& Gupta, O. P. Contemporary practice in forensic odontology. J. Oral Maxillofac. Pathol., 18(2):244-50, 2014.

Gustafson, G. Age determination on teeth. J. Am. Dent. Assoc., 41(1):4554, 1950.

Gustafson, G. \& Koch, G. Age estimation up to 16 years of age based on dental development. Odontol. Revy, 2(3):297-306, 1974.

Harris, M. J. \& Nortjé, C. J. The mesial root of the third mandibular molar. A possible indicator of age. J. Forensic Odontostomatol., 2(2):39-43, 1984.

Holden, J. L.; Clement, J. G. \& Phakey, P. P. Age and temperature related changes to the ultrastructure and composition of human bone mineral. J. Bone Miner. Res., 10(9):1400-9, 1995.

Karjodkar, F. R. Role of Dental Radiology in Forensic Odontology. In: Karjodkar, F. R. Textbook of Dental and Maxillofacial Radiology. 2nd ed. New Delhi, Jaypee Brothers Medical Publishers Ltd., 2009. pp.92963.

Kraus, B. S. \& Jordan, R. E. The Human Dentition Before Birth. Philadelphia, Lea \& Febiger, 1965. pp.218.

Kullman, L.; Johanson, G. \& Akesson, L. Root development of the lower third molar and its relation to chronological age. Swed. Dent. J., 16(4):161-7, 1992.

Kuritai, L. M.; Menezes, A. V.; Casanova, M. S. \& Haiter-Neto, F. Dental maturity as an indicator of chronological age: radiographic assessment of dental age in a Brazilian population. J. Appl. Oral Sci., 15(2):99104, 2007.

Kvaal, S. I.; Kolltveit, K. M.; Thomsen, I. O. \& Solheim, T. Age estimation of adults from dental radiographs. Forensic Sci. Int., 74(3):175-85, 1995.

Lorentsen, M. \& Solheim, T. Age assessment based on translucent dentine. J. Forensic Odontostomatol., 7(2):3-9, 1989.

Maber, M.; Liversidge, H. M. \& Hector, M. P. Accuracy of age estimation of radiographic methods using developing teeth. Forensic Sci. Int., 159 Suppl. 1:S68-73, 2006.

Masthan, K. M. K. Age and Sex. In: Masthan, K. M. K. Textbook of Forensic Odontology. New Delhi, Jaypee Brothers Medical Publishers Ltd., 2009a. pp.59-65.
Masthan, K. M. K. Age Estimation by Teeth. In: Masthan, K. M. K. Textbook of Forensic Odontology. New Delhi, Jaypee Brothers Medical Publishers Ltd., 2009b. pp.92-7.

Moorrees, C. F.; Fanning, E. A. \& Hunt, E. E. Jr. Age variation of formation stages for ten permanent teeth. J. Dent. Res., 42:1490-502, 1963.

Nolla, C. M. The development of permanent teeth. J. Dent. Child., 27:25466, 1960.

Olze, A.; Bilang, D.; Schmidt, S.; Wernecke, K. D.; Geserick, G. \& Schmeling, A. Validation of common classification systems for assessing the mineralization of third molars. Int. J. Legal Med., 119(1):22-6, 2005.

Panchbhai, A. S. Dental radiographic indicators, a key to age estimation. Dentomaxillofac. Radiol., 40(4):199-212, 2011.

Rai, B. \& Anand, S. Age estimation in children from dental radiograph: A regression equation. Internet J. Biol. Anthropol., 1(2), 2007. Available from: http://ispub.com/IJBA/1/2/6049

Ritz-Timme, S.; Cattaneo, C.; Collins, M. J.; Waite, E. R.; Schütz, H. W.; Kaatsch, H. J. \& Borrman, H. I. Age estimation: the state of the art in relation to the specific demands of forensic practise. Int. J. Legal Med., 113(3):129-36, 2000.

Schour, I. \& Massler, M. The development of the human dentition. J. Am. Dent. Assoc., 20:1153-60, 1941.

Solari, A. C. \& Abramovitch, K. The accuracy and precision of third molar development as an indicator of chronological age in Hispanics. J. Forensic Sci., 47(3):531-5, 2002.

Tobias, V. P. The Skulls Endocasts and Teeth of Homo habilis. Olduvai Gorge, Volume IV. Cambridge, Cambridge University Press, 1991. pp.50-80.

Van Heerden, P. J. The mesial root of the third mandibular molar as a possible indicator of age. Dissertation for Diploma in Forensic Odontology. London, London Hospital Medical College, 1985.

Vandevoort, F. M.; Bergmans, L.; Van Cleynenbreugel, J.; Bielen, D. J.; Lambrechts, P.; Wevers, M.; Peirs, A. \& Willems, G. Age calculation using $\mathrm{X}$-ray microfocus computed tomographical scanning of teeth: a pilot study. J. Forensic Sci., 49(4):787-90, 2004.

Verma, A. K.; Kumar, S.; Rathore, S. \& Pandey, A. Role of dental expert in forensic odontology. Natl. J. Maxillofac. Surg., 5(1):2-5, 2014.

Whittakar, D. K. \& McDonald, D. G. Age Determination from Teeth. A Color Atlas of Forensic Dentistry. London, Wolfe Medical Publications Ltd., 1989. pp.58-66.

Willems, G. A review of the most commonly used dental age estimation techniques. J. Forensic Odontostomatol., 19(1):9-17, 2001.

Yang, F.; Jacobs, R. \& Willems, G. Dental age estimation through volume matching of teeth imaged by cone-beam CT. Forensic Sci. Int., 159 Suppl. 1:S78-83, 2006.

Yun, J. I.; Lee, J. Y.; Chung, J. W.; Kho, H. S. \& Kim, Y. K. Age estimation of Korean adults by occlusal tooth wear. J. Forensic Sci., 52(3):678-83, 2007.

\author{
Corresponding author: \\ Dr. Firas Alsoleihat \\ Associate Professor \\ Craniofacial development dental morphology and oral \\ histology \\ Department of Conservative Dentistry \\ School of Dentistry \\ The University of Jordan \\ Amman 11942 \\ JORDAN
}

E-mail: firas.alsoleihat@ju.edu.jo

Received: 20-10-2016

Accepted: 08-03-2017 